\title{
Global constitutionalism: A practical universal
}

\author{
Anthony F Lang, Jr. \\ University of St Andrews \\ Corresponding author. Email: Al51@st-andrews.ac.uk
}

\begin{abstract}
This article argues that this special section reveals a practical global constitutionalism, or one that integrates a liberal constitutional set of ideas with the histories and practices of Asian states.
\end{abstract}

Keywords: global constitutionalism; comparative constitutionalism; practical constitutionalism

\section{Introduction}

This special issue explores global constitutionalism in Asia. Along with a recently published edited collection on this topic, these articles provide new and important insights into how global norms are shaping and being shaped by legal and political dynamics in Asian national contexts. ${ }^{1}$ The articles here circle around and sometimes directly confront one of the challenges that has emerged in recent years within the discourse on global constitutionalism: the applicability of a largely liberal, democratic ideal in non-liberal and non-democratic national contexts. In fact, there exist two interrelated, but slightly different critiques of global constitutionalism: (1) that global constitutionalism fails to account for the diversity of legal and political ideas and practices; and (2) that the existing international legal and political order relies upon a history of colonialism and its continuation in neoliberalism today. ${ }^{2}$

The articles in this collection do not necessarily agree with this framing of the problem, and not all the authors would claim that there is a such problem. In my concluding reflections for this special issue, however, I use the articles here to address this challenge to the supposed liberal universalism of global constitutionalism. I say 'supposed' because I would argue that global constitutionalism can indeed be global and integrate a diversity of ideas and perspectives in its description and analysis of, and advocacy for, constitutional ideals. $^{3}$ Specifically, this concluding article focuses more on the first problem (the

\footnotetext{
${ }^{1}$ Takao Suami, Anne Peteres, Dimitri Vanoverbeke, and Mathias Kumm (eds), Global Constitutionalism from European and East Asian Perspectives (Cambridge University Press, Cambridge, 2018).

${ }^{2}$ For one clear and succinct provocation along these lines, see Vidya Kumar, 'Towards a Constitutionalism of the Wretched: Global Constitutionalism, International Law, and the Global South', 27 July 2017, <https:// voelkerrechtsblog.org/towards-a-constitutionalism-of-the-wretched>.

${ }^{3}$ See James Tully, Jeffrey L. Dunoff, Anthony F Lang Jr, Mattias Kumm and Angje Weiner, 'Introducing a Global Integral Constitutionalism' (2016) 5(1) Global Constitutionalism 1-15.

(C) The Author(s), 2021. Published by Cambridge University Press. This is an Open Access article, distributed under the terms of the Creative Commons Attribution licence (https://creativecommons.org/licenses/by/4.0/), which permits unrestricted re-use, distribution, and reproduction in any medium, provided the original work is properly cited.
} 
liberalism of constitutionalism) rather than the second (the colonial heritage of global constitutionalism), although it might help us to think about the second problem. On the basis of reading these pieces, and by integrating some additional material, I conclude that while there most certainly exists an assumption of liberal universalism in much of the global constitutionalism literature (although not all), these articles demonstrate how the practical tasks of making a constitution function in the contemporary political order have and will continue to move states toward global norms. The migration and interaction of these ideas and practices reinforce what I call 'practical global constitutionalism', which is the idea that the global ideals of democracy, human rights and the rule of law only work when they are integrated into existing social and economic systems. That is, there is no ideal global constitutional order, just as there is no ideal liberal constitutional order. All ideas - liberal, constitutional and otherwise - will be refracted through the lenses of particular localities, states and regions. Recognizing this diversity enables us to understand and advance social, legal and political ideas that can benefit all peoples. ${ }^{4}$

This article starts by addressing the problem of global constitutionalism, universalism and liberalism. I suggest that while the idea of global constitutionalism may have originated in liberal domestic and international legal systems, it has become a much wider and more integrative project. This does not mean it will result in a global state but, as the articles in this issue demonstrate, the integration of the rule of law, democracy and human rights into national and regional legal systems suggests that these ideas can be adapted and adjusted to different cultural contexts. This process of adaptation is not easy, and I look to the idea of contestation as one means by which norms move from the global to the regional and national contexts. After establishing this more general point, I briefly review the contributions, highlighting what they reveal about how states integrate such norms that, while contested, become part of Asian contexts in a variety of ways. I conclude with some reflections on ways forward not just for Asian constitutionalism but for how theorists of global constitutionalism can learn from the insights generated by these articles. ${ }^{5}$

\section{Is global constitutionalism just liberal universalism?}

Constitutionalism is often associated with liberalism; indeed, the latter term often modifies the former. Despite their family resemblance, however, the two terms differ in important ways. Liberalism is a political ideology that privileges liberty, individualism, rights and progress. Constitutionalism is an institutional framework used to channel constituent power into constitutional form, which balances power, advances the rule of law and ensures the protection of rights broadly defined. ${ }^{6}$ The protection of rights reveals the link between contemporary constitutionalism and liberalism, although rights are more than the civil and political rights of the neoliberal model. In addition, liberalism

\footnotetext{
${ }^{4}$ For a parallel argument on the universalism of global ethics, see Anthony F Lang Jr, 'Constructing Universal Values? A Practical Approach' (2020) 34(3) Ethics \& International Affairs, 267-77.

${ }^{5}$ One caveat is important to highlight at the outset. All the articles in this collection have been written by legal scholars. I write mine from the perspective of a political theorist, albeit one with an interest in international law. As such, my goal here is to bring out the political in global constitutionalism, which requires drawing general conclusions from the detailed legal analyses herein. The political theorist's perspective is not better than that of the legal scholar, but it is important to highlight this difference in our respective starting points.

${ }^{6}$ See Martin Loughlin and Neil Walker (eds), The Paradox of Constitutionalism: Constituent Power and Constitutional Form (Oxford University Press, Oxford, 2008).
} 
does not always embrace a separation of power and the communal aspects of constituent power. These distinctions explain how states in Asia and elsewhere that are not liberal can be described as being constitutional.

In the contemporary global political system, many in Europe and North America now argue that liberalism and democracy are under siege. ${ }^{7}$ During 2019, traditional liberal states found their domestic political systems embroiled in distinctively anti-liberal dynamics. In September 2019, the British parliament was prorogued over Brexit, while the American political system found itself dominated by a president who was more interested in point scoring than governing. Germany is struggling with immigration, leading to challenges to its liberal ideology of acceptance and toleration. In France, resistance to economic liberalization in the public sector has generated political unrest. The European Union, often seen as a site of regional if not global constitutional values, has sunk into a miasma of bureaucratic governance, contributing not just to Brexit but to discontent among populations in many of its member states.

Outside of these European and North American contexts, liberalism has lost even more ground. While there are examples from around the world, the Asian context - which is explored in more detail in this special issue - provides its own evidence. In China, there are worrying signs of a powerful executive, no real separation of powers and a very limited conception of rights as guarantees of free speech or free assembly. Continuing conflicts in Hong Kong attest to the refusal of the Chinese authorities to ensure basic freedom of movement, assembly and free speech. India, the largest democracy in the world, has moved towards an increased reliance on Hindu nationalism as its legitimizing device, reinforced by an emerging cult of personality surrounding its current prime minister.

The articles that follow suggest that this story may not be so simple, however. Once we begin digging into the political, legal and even ethical practices of Asian states, the picture becomes more complex. Samuli Seppänen's discussion of interpretative strategies undertaken by different agents in the Chinese context reveal a more complex picture concerning the rule of law. The claims here are not that China should be seen as a paragon of the rule of law, but that efforts to use the rule of law discourse in different ways may well produce something different than our expectations of what the dominant liberal discourse assumes. The article by Rehan Abeyratne reveals an even more important point. Rather than focus on the illiberalism of the Indian executive, if we focus on the Indian judiciary we find a powerful regional agent helping to construct new forms of indigenous jurisprudence that has shaped and been shaped by courts in Sri Lanka and Bangladesh. Indeed, as new work in comparative constitutional law is revealing, states such as India are beginning to play a more important role in the transfer of constitutional norms, as courts around the world cite their own cases rather than those of the United States, United Kingdom or France. ${ }^{8}$

What of the global sphere? The domestic resistance to liberalism is driven in part by worries about cosmopolitan elites overriding traditional domestic political systems, resulting in a dual critique of liberalism. ${ }^{9}$ Nationalisms around the world have found

\footnotetext{
${ }^{7}$ See Adrian Pabst, The Demons of Liberal Democracy (Polity Press, Cambridge, 2019); Steven Levitsky and Daniel Ziblatt, How Democracies Die: What History Reveals About Our Future (Penguin, Harmondsworth, 2018); David Runciman, How Democracy Ends (Profile Books, London, 2018).

${ }^{8}$ See Ran Hirschl, Comparative Matters: The Renaissance of Comparative Constitutional Law (Cambridge University Press, Cambridge, 2014).

${ }^{9}$ See Stephen Walt, 'The Collapse of the Liberal World Order' Foreign Policy, 26 June 2016, <https:// foreignpolicy.com/2016/06/26/the-collapse-of-the-liberal-world-order-european-union-brexit-donaldtrump $>$.
} 
economic globalism, immigration and international law to be the perfect enemies. While major war has not yet broken out, discrete uses of violence by great powers appear to be the norm; the targeted killing of a senior Iranian general by the United States is the most recent example. ${ }^{10}$ Civil and regional conflicts have grown in intensity and increasing levels of inequality around the world have accelerated the collapse of liberalism. The rise of the middle class in states such as China and India has increased absolute levels of wealth worldwide, but the persistence of radical forms of inequality in many countries and the loss of the middle classes in European and North American contexts has undermined the potential for a stable class that can advocate for rights and equality. The loss of traditional forms of employment, with no guarantees of a lifelong pension, has encouraged populism and destabilized the global trade and financial order. While that order may not necessarily have been designed to redistribute wealth, it is perceived to be exacerbating inequality to the extent that it has become a target for populist agitation.

Ironically, the emergence of climate change may also be undermining liberalism. On the one hand, the excessive uses of fossil fuels to power global capitalism has tarnished the free market ideology. The response for some has come in the form of a 'green new deal' that advances a more redistributive economic model, both nationally and globally. ${ }^{11}$ An alternative response, and one that is more worrying for liberal politics, has come from China. Many have looked with admiration to the way in which the Chinese managed economy has pushed forward reforms to its energy and environmental sector in a rapid and efficient way. The ability of the state to undertake this agenda, however, results in large part from the lack of any real political opposition from business, industry or financial services, the parties opposed to change in many liberal democracies. Because pluralist democratic politics allows those economic interests to push back against rapid environmental policy change, the Chinese model is seen as beneficial for the environment. What does it matter if political and economic liberties are put at risk if the overriding problem of the climate can be addressed so rationally?

The articles in this special issue suggest that the story told above is not so simple or clear. The domestic legal and political practices of the states discussed in these articles reveal interactions at the national, regional and international levels in which different actors are trying to advance democracy and the rule of law. What they point to is not a triumph of liberalism, but an ongoing effort to connect national legal and political practices to regional and global ones. These efforts suggest that what is emerging is not a liberal constitutionalism, but new forms of constitutionalism. I call this new form practical global constitutionalism, for it reflects an ongoing effort to bring together ideas and practices in order to improve the lives of citizens around the world. In fact, the evidence from these articles suggests that it is not that liberalism needs rescuing (as many commentators in the West assume), but rather that constitutionalism has and will continue to be a framework within which power can be channelled and moderated.

Constitutionalism takes from liberalism the centrality of rights and effective democratic governance, but it also respects the importance of community, is wary of power and seeks to create means to ensure that institutions function effectively. Global constitutionalism also reflects these values, but it recognizes that the myth of domestic polities

\footnotetext{
${ }^{10}$ Iran's Qasem Soleimani: Why the US Had Him in Its Sights', BBC News, 3 January 2020, <https:// www.bbc.co.uk/news/world-middle-east-50980093>.

${ }^{11 ' T h e ~ G u a r d i a n}$ View on a Green New Deal: Why We Need it Now', Editorial, The Guardian, 12 May 2019, <https:/www.theguardian.com/commentisfree/2019/may/12/the-guardian-view-on-a-green-newdeal-we-need-it-now>.
} 
kept separate from global forces is no longer viable. That is, the world is globalized and there is no way to turn back from this. Rather than lament this and look for solutions in state ideologies or populist visions of a mythical domestic people, we need to articulate, map out and propose new ways to institutionalize a global constitutional order.

Mattias Kumm sets out a perspective on global constitutionalism that parallels the points made here. In his account, while global constitutionalism - along with liberal constitutionalism - might have its origins in Enlightenment ideas from the West, it need not remain there. Moreover, its origins in a particular time and place do not mean that peoples from around the world cannot engage with it and seek to improve upon it. As Kumm argues, if we undertake an 'affirmative genealogy', the result is not a discrediting of global constitutionalism, but an opportunity to see how it continues to be reshaped by practices and ideas from around the world. ${ }^{12}$ Using the example of the post-World War II imposition of constitutions on Germany and Japan, Kumm suggests that such an imposition, while the result of a military defeat and admittedly a partially imperial project, does not necessarily mean that global constitutionalism cannot evolve and adapt to particular national contexts:

If constitutionalism is effectively imposed on a particular nation or the world, as it was Germany and Japan after World War II and as it arguably was on the whole of the world by way of the UN Charter, then it becomes decisive whether those subjected to the order generally embrace its basic principles over time, make it their own, engage with it, participate within it and, if they deem necessary, modify aspects of it as they deem fit. One of the decisive features of constitutionalism is that it legally authorises and highlights such participatory engagement and rejects the lethargic attitude of mere subjects as unworthy of the office of citizenship. ${ }^{13}$

Indeed, the ability to modify formally (through amendments) or informally (through practice) constitutional frameworks makes them an ideal vehicle to adapt what was a Western ideal to diverse contexts.

Kumm's account parallels my own, although we begin from different theoretical and disciplinary starting points. Kumm has been an important legal theorist of cosmopolitanism and human rights as frameworks through which we can address global constitutionalism. ${ }^{14}$ My focus has been more on the politics of power, in terms of both constituent power and the balance of powers in a global constitutional system. ${ }^{15}$ What we share, though, is the idea that global constitutionalism should not be understood as a simple universalism imposed by powerful states on weaker ones. While imperialism has used, and continues to use, law in its service, not every constitutional idea should be tarred with the colonial brush. As the articles in this collection demonstrate, attending to the diversity

\footnotetext{
${ }^{12}$ Mattias Kumm, 'On the History and Theory of Global Constitutionalism' in Suami (n 1) 183.

${ }^{13} \mathrm{Kumm}$ (n 12) 189.

${ }^{14}$ Mattias Kumm, 'The Cosmopolitan Turn in Constitutionalism: On the Relationship Between Constitutionalism in and Beyond the State' in Jeffrey Dunoff and Joel Trachtman (eds.) Ruling the World: Constitutionalism, International Law and Global Governance (Cambridge University Press, Cambridge, 2009) 258.

${ }^{15}$ Anthony F Lang Jr, 'Global Constituent Power: Protests and Human Rights', in Aidan Hehir and Robert Murray (eds), Protecting Human Rights in an Age of Uncertainty (Routledge, London, 2017) 19 and Anthony F Lang Jr, 'Global Constitutionalism as Middle Ground Ethics', in Cornelia Navari (ed), Ethical Reasoning in International Affairs: Arguments from the Middle Ground (Palgrave, Basingstoke, 2013) 106.
} 
of ways in which global constitutionalism is shaping and being shaped by practices in these Asian states provides better insights into contemporary global politics and law than a simple denunciation of global constitutionalism as an imperial agenda.

\section{Contesting global constitutionalism: The Asian example}

The integration of constitutional ideas into national and regional contexts is no easy task. It may well begin by imposing norms, but the response to that assertion of power leads to forms of contestation. However, contestation is not necessarily a bad thing; indeed, it often leads to new norms, revised and enhanced by the process of interaction and contestation. As Antje Wiener and I note in our introduction to the Handbook on Global Constitutionalism:

By linking contestation (as a localized activity) with constitutionalisation (as a globalised process) it is possible to facilitate a relational account of global constitutionalism as a mosaic of pluralist constitutional narratives rather than a single encompassing normative order. ${ }^{16}$

Wiener has developed the idea of contestation and its links to global constitutionalism more extensively in her own work. ${ }^{17}$ While not direct demonstrations of contestation, the ways in which the Asian states and the wider Asian region have integrated global constitutional norms suggest one way of seeing how contestation and pluralism can function. In this section, I use the frame of productive contestation to demonstrate the benefits of these encounters.

Cheryl Saunders provides an overview of constitutional transformation and contestation. She asks how globalization has changed the nature of constitutions, pointing us to the ways in which global dynamics shape the national constitutional framing of states, both in Asia and elsewhere. Her analysis of transformation is important and timely, and gestures towards how such transformations are not without contestation. Rather than see these transformations as examples of the collapse of either constitutions or global constitutionalism, the ways in which Asian states have had to adjust to the global economic crises connect constitutionalism to the social and economic dynamics that shape global and national politics. Saunders expresses concerns about the difficulties and challenges revealed by these processes, but the changes brought about by globalization are leading Asian states to undertake and adopt new constitutional forms.

Not every effort to integrate global constitutional norms into states succeeds. The article by Surabhi Chopra on the Philippines demonstrates how the aspiration to integrate socio-economic rights in its 1987 constitution has not resulted in justiciable rights or advanced the protection of those rights. The aspirational constitution has yet to transform the society. Yet perhaps the standard of achieving such rights is not where we should focus our attention; instead, we might rather recognize that hardly any liberal democratic states have truly incorporated socio-economic rights, with most states focused on civil and

\footnotetext{
${ }^{16}$ Anthony F Lang Jr and Antje Wiener, 'A Constitutionalising Global Order: An Introduction', in Anthony F Lang Jr and Antje Wiener (eds), Handbook on Global Constitutionalism (Edward Elgar, Cheltenham, 2017) 1 at 16-17.

${ }^{17}$ See Antje Wiener, A Theory of Contestation (Springer, Dordrecht, 2014) and Contestation and Constitution of Norms in Global International Relations (Cambridge University Press, Cambridge, 2018).
} 
political rights. The aspiration of the framers of the Philippines has created a discourse and a standard that, while not currently being put into practice by the Supreme Court, has created a vision and ideal that may well slowly transform that society. Indeed, contestation requires a discourse on which such efforts rely in order to truly succeed. If anything, this article provides some hope and guidance in terms of framing a constitution and the lessons that can be learned from the failed efforts of courts to act on those constitutional ideals.

The case of Taiwan, as explained in the article by Chien-Chih Lin, gives us a different perspective on how constitutional norms can migrate and adapt. At one level, the story told here is a simple one of how judges and advocates trained in the West brought constitutional ideals to Taiwan. But there is a hint of something more complex going on. Lin notes that while legal education played an important role, perhaps equally important was the anxiety in political and legal circles about being 'modern'. This quest for modernity has been a staple part of the postcolonial landscape of the twentieth century, leading to various failed forms of development throughout the world. In this case, however, it has led to the adoption of a robust set of norms concerning judicial review and human rights protections. While identifying any single causal factor is complex, Lin's article shows us that contestation is not necessarily a set of violent clashes, but can even result from forms of ontological anxiety about modernity.

Three of the articles focus further on the role of justices in the adaptation of constitutional cultures, but in rather creative ways. In the case of the Pacific Islands, Anna Dziedzic explains how foreign judges serving in various countries in the region help to create a regional constitutionalism that overlaps directly with global constitutionalism. There is a rich body of literature on drawing on foreign judicial systems around the world; indeed, in the US context, this is a point of conflict on the Supreme Court. ${ }^{18}$ Yet this article asks us to go deeper than this question. Rather than just foreign rulings, this article looks at how the existence of foreign judges in a legal system might change the constitutional order and reinforce global constitutional norms. One question to ask of these practices, however, is how helpful the term 'foreign' is here. If there exists a shared legal culture, does foreign only apply to citizenship status? If so, how helpful is this marker? Dziedzic does not raise this question, but her empirical detail helps us to ask this deeper question about the very idea of foreign and domestic when considering global constitutionalism and its impact on domestic legal orders.

Rehan Abeyratne argues that Indian jurisprudence has had a profound impact on various states in both Southeast and East Asian legal contexts. The Indian Supreme Court has been one of the most active and influential courts around the world. ${ }^{19}$ Abeyratne focuses on the basic structure doctrine and public interest litigation as developed within Indian jurisprudence. The article then traces the influence of these ideas in Sri Lanka and Bangladesh, finding more of an Indian influence in Bangladesh than in Sri Lanka. In explaining this divergence, Abeyratne highlights the power dynamics among the three countries, suggesting that Sri Lanka's more conflictual political relationship with India might explain the divergence. This suggests that while contestation can be a positive

\footnotetext{
${ }^{18}$ See Stephen Breyer, The Court and the World: American Law and Global Realities (Alfred A Knopf, New York, 2015), which sets out a case for the benefits and indeed necessity of drawing on US jurisprudence drawing on foreign courts.

${ }^{19}$ See Ran Hirschl, Comparative Matters: The Renaissance of Comparative Constitutional Law (Oxford University Press, Oxford, 2014) 73-74.
} 
process in some contexts, when contestation becomes conflict, cultural convergence may not happen. While there is still an influence, it has certainly been mitigated by the conflict between the two states.

Yoon Jin Shin's study of South Korea gives us an additional insight into the institutional frameworks through which constitutional ideas migrate. South Korea played a key role in creating the Association of Asian Constitutional Courts and Equivalent Institutions (AACC). This regional institution has given judges and others the ability to interact in formal settings through which constitutional ideas can be shared. While there are undoubtedly disagreements, this institutional form provides a counter to the problem identified in the relationship between India and Sri Lanka. The power differential between the two (with one much more powerful than the other) would not exist within a formal regional institution such as the AACC. Indeed, this has long been part of liberal institutionalist theories within international relations, where conflict can be turned into cooperation through robust institutions. ${ }^{20}$ Much of this literature in international relations focuses on economic cooperation, so this article points us towards how these dynamics might work in the realm of global constitutionalism.

Finally, the article by Samuli Seppänen on China's constitutional context raises a different kind of question. Drawing on the distinction between formalist and antiformalist reasoning, Seppänen demonstrates how the Chinese Communist Party (CCP) employs formalist language to advance itself as a 'scientific' and modern country, while it relies upon anti-formalist ideas to critique an excessive legalism in the judiciary. The article nicely conveys how concepts that have played one role in the European and North American judicial cultures have been reversed in some ways in the Chinese legal culture. Rather than a form of contestation leading to adaptation, this article suggests that scholars who rely upon hermeneutic and/or discursive ideas developed in one legal context need to pay closer attention to how those concepts work elsewhere. Contestation and adaptation here might be more for us as scholars of global constitutionalism than for those in the real world of constitutional politics.

\section{Conclusion}

I began this article by suggesting that global constitutionalism is not simply a liberal imposition on the rest of the world. The articles in this special issue reveal that the forms of adaptation of constitutional norms in the Asian context are more complex than a simple assertation of power. By using the idea of contestation as a theoretical framework, I have highlighted the politics that underlie forms of global constitutionalism in the current global legal and political order.

There is no single pathway by which global constitutionalism will evolve over the coming years. Nor should it be seen as a simple narrative of progress, with human rights, democracy and the rule of law emerging triumphant. Rather, we see is a range of different practices and actors seeking to understand and act at the intersection of law and politics. The practical global constitutional order emerging here is not complete, nor will it ever

\footnotetext{
${ }^{20}$ See Robert Keohane, After Hegemony: Cooperation and Discord in the World Political Economy (Princeton University Press, Princeton, NJ, 1984).
} 
be. But it is to these messy forms of contestation that theorists of global constitutionalism need to pay most attention if they wish to fully understand and advance a more just world for all.

Cite this article: Lang AF. 2021. Global constitutionalism: A practical universal. Global Constitutionalism 10: 367-375, doi:10.1017/S2045381721000149 